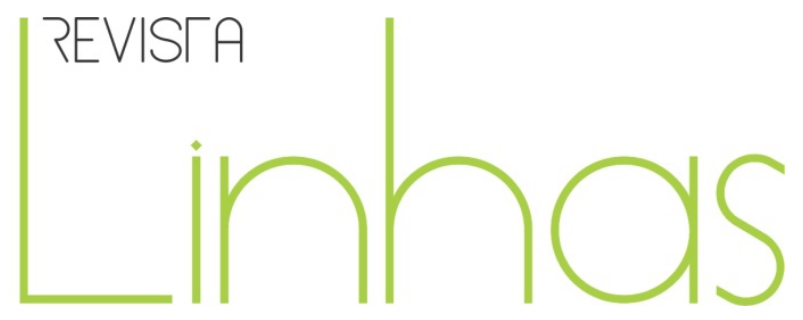

\title{
Museu da Escola "Professora Ana Maria Casasanta Peixoto": um compromisso com a história da educação mineira
}

\begin{abstract}
Resumo
Este artigo apresenta uma narrativa ${ }^{1}$ sobre a constituição, a trajetória e as diretrizes que orientaram o trabalho no Museu da Escola "Professora Ana Maria Casasanta Peixoto". Criado em Belo Horizonte como Centro de Memória da Educação, integrou o Centro de Referência do Professor ${ }^{3}$, instituição que empreendeu, entre 1994 e 2005, uma ampla proposta de formação continuada para os docentes da rede pública de Minas Gerais. Além da narrativa, pretendemos enfatizar o lugar ocupado pelo museu da escola no Brasil, em relação às ações de resgate e preservação da história da educação e de seu patrimônio, tangível e intangível, uma experiência inédita, pioneira e modelar que inspirou a criação de espaços de salvaguarda da memória educacional em outros estados brasileiros.
\end{abstract}

Palavras-chave: História da Educação; Acervos escolares; Cultura material escolar; Patrimônio imaterial; Preservação.

\section{Para citar este artigo:}

FONSECA, Nelma Marçal Lacerda. Museu da escola "Professora Ana Maria Casasanta Peixoto": um compromisso com a história da educação mineira. Revista Linhas, Florianópolis, v. 15, n. 28, p. 77-99, jan./jun. 2014 .

DOI: $10.5965 / 1984723815282014077$

http://dx.doi.org/10.5965/1984723815282014077

\footnotetext{
${ }^{1}$ Parte desta narrativa, a respeito da história da criação do Museu da Escola, tem por base as informações passadas pela professora Ana Maria Casasanta, na entrevista gravada no programa de história oral do Museu da Escola, em 2002.

${ }^{2}$ Ana Maria Casasanta Peixoto (1943-2008), pedagoga, doutora em História e Filosofia da Educação, Prêmio Diogo de Vasconcelos de Historiografia Mineira, foi autora, pesquisadora e professora da FaE/UFMG; propositora e fundadora do Centro de Memória da Educação; aposentando-se na UFMG, criou o Mestrado em Educação da PUC/MG.

${ }^{3}$ O Centro de Referência do Professor foi criado pela Lei Estadual no 11.406 de 1994, que definiu uma nova estrutura administrativa na Secretaria de Estado de Educação de Minas Gerais. O centro ocupou o prédio sede da Secretaria, à Praça da Liberdade, e constitui-se em três segmentos: o Centro de Memória da Educação, a Biblioteca do Professor e o Laboratório de Currículos. Considerado um marco na educação mineira por conjugar passado, presente e futuro, foi uma experiência exemplar para outros estados brasileiros, que criaram seus centros a exemplo do de Minas, entre eles o Centro de Referência em Educação Mário Covas, em São Paulo. Após mais de uma década de serviços prestados à educação mineira, o Centro de Referência do Professor foi extinto em 2006, para desocupação do prédio a fim de torná-lo sede do Museu das Minas e do Metal, gerenciado pela OGX, uma das empresas de Eike Batista, no Circuito Cultural Praça da Liberdade.
} 


\title{
Museum of the School "Professora Ana Maria Casasanta Peixoto": a commitment with the history of education of Minas Gerais
}

\begin{abstract}
This article presents a narrative of the formation, the trajectory and the guidelines which oriented the research at the Museum of the School Professora Ana Maria CasasantaPeixoto. It is located in Belo Horizonte and constitutes an integral part of the teachers' reference center. The museum, from 1994 to 2005, played an ample role in the formation of public school teachers in Minas Gerais. Besides the narrative, the importance of the museum as to both the preservation and recovery of the history of education as well as its tangibles and intangibles is highlighted. It constituted a unique experience, which inspired the foundation of other areas for the preservation of educational history in other states in Brazil.
\end{abstract}

Keywords: History of education; School heritage;

School material heritage; Oral memory; Preservation. 


\title{
A constituição do espaço privilegiado da memória da educação de Minas Gerais
}

\begin{abstract}
O Museu da Escola exerce seu papel na sociedade ao mostrar que a educação pertence a uma história que tem continuidade, rupturas, consensos e contradições. Dessa forma, ele oferece aos mineiros e, sobretudo, aos educadores, um outro ângulo de apreensão das questões pedagógicas. Órgão vivo, instrumento de cultura e de distribuição do saber, o Museu da Escola tem seu lugar na cultura mineira. Cerrar suas portas significa que, mais uma vez, Minas abre mão de sua história. Esse gesto tem um significado prático, mas traz consigo, também, uma profunda dimensão simbólica. Ele pode sugerir que diante do fascínio das inovações tecnológicas, que se fazem cada vez mais velozes e radicalmente transformadoras, Minas estaria abrindo mão de seus deveres para com a escola pública. E, ao fazê-lo, além de virar as costas aos compromissos firmados pelos defensores do regime republicano, estaria privando parcelas significativas de nossa população do acesso a instrumentos necessários ao exercício da cidadania. ${ }^{4}$
\end{abstract}

O Museu da Escola "Professora Ana Maria Casasanta Peixoto" teve origem em fatos ocorridos no estado de Minas Gerais em 1990, ano em que foi lançado, pela Organização das Nações Unidas para a Educação, Ciência e Cultura (Unesco), o Ano Internacional da Alfabetização, um movimento mundial com vistas a erradicar o analfabetismo entre as nações. Naquele ano, na Faculdade de Educação da Universidade Federal de Minas Gerais (FaE/UFMG), um grupo de professores se reuniu para elaborar um plano de ação, não só para marcar o evento, mas também para definir estratégias que contribuíssem no enfrentamento dos graves problemas constatados na educação mineira.

Ana Maria Casasanta fazia parte desse grupo, sendo a propositora, entre outras atividades, da organização de uma exposição que enfatizasse a formação e atuação do professor, seus métodos e processos de ensino, os materiais utilizados em sala de aula, enfim, a cultura escolar do passado. Entre os objetivos por ela propostos na organização dessa exposição, alguns eram mais imediatos, como: sensibilizar a sociedade e o governo para a necessidade urgente de recuperar os valores da educação em Minas Gerais, que

\footnotetext{
${ }^{4}$ Extraído do artigo da professora Ana Maria Casasanta, intitulado "A memória da escola", publicado no Jornal Estado de Minas, de Belo Horizonte, em 24 de maio de 2006, a propósito dos rumores, naquele momento, sobre o fechamento do Museu da Escola.
} 
registrava altos índices de repetência e evasão escolar; chamar atenção para a importância da formação inicial e continuada dos docentes e de seu papel na sociedade e, especialmente, dar início a uma política de preservação da memória do ensino e dos bens patrimoniais das escolas, tendo em vista a escassez de fontes para a pesquisa no campo da história da educação e o descarte dos registros e do acervo material que ocorria nas escolas.

Após muitos esforços em direções diversas para obter apoio, foi realizada, no Centro Cultural da UFMG, a exposição intitulada "Era uma vez uma escola...”, que reuniu materiais cedidos por várias escolas públicas de Belo Horizonte visitadas pela equipe. A mostra causou impacto no meio acadêmico e entre os visitantes que puderam observar a reconstituição de salas de aula de períodos diversos, de reformas de ensino, tendo destaque o mobiliário, as cartilhas de alfabetização e os objetos escolares plenos de significado ao imaginário individual e coletivo dos belo-horizontinos. Mas o mais importante desse movimento foi o alcance do principal objetivo - sensibilizar para a importância das ações de identificação dos bens patrimoniais referentes à história da educação mineira, que haviam escapado do descarte, e dar início à sua recolha, tratamento e guarda, o que abordamos na sequência.

As preocupações da professora Ana Maria em relação à salvaguarda desses bens se deviam ao compromisso pessoal e profissional que assumiu com a memória do ensino em Minas Gerais, tendo em vista sua atuação na docência da disciplina História da Educação, tanto na graduação do curso de pedagogia quanto na pós-graduação na FaE/UFMG. Movida pela crença na importância da preservação do patrimônio escolar como testemunho da história das sociedades ao longo do tempo, das correntes filosóficas e tendências pedagógicas no campo da educação, sabia que deveria ir além da empiria e buscar comprovações nas pesquisas que realizava. Neste sentido, a experiência de pesquisa registrada no Guia de Fontes para o estudo do Ensino Primário e Normal em Minas Gerais (PEIXOTO; PRATES, 1994), financiada pela Fundação de Amparo à Pesquisa de Minas Gerais (Fapemig), havia revelado um quadro ainda mais alarmante do que se supunha: em Belo Horizonte e nas cidades históricas de seu entorno, inexistiam ações de guarda e preservação nas escolas, o que apontava a urgência de iniciativas para a criação 
de espaços organizados e sistematizados de fontes para pesquisas referentes à educação mineira 5 .

O guia de fontes apontou as escolas que ainda possuíam mobiliários, materiais e documentos históricos - eram os antigos grupos escolares, situados nas áreas nobres das cidades, criados em Minas Gerais em 1906, à época da Reforma João Pinheiro. O poder público procurava cuidar da preservação dos prédios escolares; a direção das escolas se preocupava com a conservação dos móveis antigos, quase sempre dos gabinetes, e muito pouco em termos de documentos escritos, material didático e objetos que iam sendo substituídos ao longo do tempo. Materiais pedagógicos importantes para a pesquisa historiográfica, como cartilhas e livros adotados, manuais de ensino, diários de classe, planos de aula, cartazes de leitura, atas de reunião, entre outros, encontravam-se, geralmente, em estado precário de conservação, jogados em porões sujeitos a todo o tipo de intempérie, o que acelerava a ação do tempo.

Aquele contexto era angustiante para alguém, como a professora Ana Maria, que tinha por objeto de estudo e pesquisa justamente tais registros. O que aconteceu na sequência, embora tenha favorecido a busca por solução, por outro, acentuou sua preocupação, pois, ao término da referida exposição, a direção das escolas não quis receber os objetos emprestados, alegando falta de espaço físico. Tal situação motivou Ana Maria a idealizar o espaço adequado para guarda e preservação daquele acervo num projeto mais amplo, com objetivos mais ambiciosos, o que veio a ser o Centro de Memória da Educação.

Ao mesmo tempo, a Secretaria de Estado de Educação de Minas Gerais deixava o prédio que ocupara na Praça da Liberdade desde os anos 1930, chamado Palácio da Educação que, inaugurado com a Nova Capital ao final do século XIX, já não suportava a grande estrutura administrativa em que havia se tornado. Outra questão que se associou

\footnotetext{
5 Atualmente, em Belo Horizonte, sobressaem-se como espaços para a pesquisa: o Centro de Documentação, Pesquisa e Memória (CEDOC), da FaE/UFMG; o Arquivo Público Mineiro; o Arquivo Público da Cidade; a Hemeroteca; a Biblioteca Pública de Minas Gerais; as bibliotecas da Faculdade de Educação/UFMG, do Centro de Alfabetização, Leitura e Escrita da Faculdade de Educação/UFMG (Ceale), da Sala Helena Antipoff, dessa universidade, do Instituto de Educação de Minas Gerais, da PUC/MG e a biblioteca do extinto Centro de Referência do Professor, hoje "Biblioteca Bartolomeu Campos Queiroz", situada no campus da Secretaria de Estado de Educação, no bairro Gameleira.
} 
a estas e que teve um peso importante na solução do problema foi a grande insatisfação dos professores públicos, em greve no estado já de longo tempo por aumento salarial, melhores condições de trabalho e investimentos na educação.

Este contexto foi um dos principais argumentos utilizados por Ana Maria para levar o Secretário de Educação a acolher a ideia de transformar o prédio num centro de formação continuada para os docentes mineiros. A princípio, a ideia do secretário era que o prédio fosse utilizado somente para museu da educação mineira. A professora argumentou que não havia acervo bastante para ocupar os três andares do prédio, enfatizando, porém, ser mais apropriado para abrigar um espaço com diversos serviços que atendessem às grandes demandas de aperfeiçoamento dos professores, levando em conta a precariedade de sua formação inicial.

Aquela conjuntura propiciou entendimentos entre o secretário, a equipe da FaE/UFMG e a equipe constituída pela Secretaria, na decisão de acatar tais ideias e destinar o prédio à formação dos professores. Após essa conjunção de esforços e de muito trabalho, aconteceu a inauguração, em outubro de 1994, do Centro de Referência do Professor, espaço para o diálogo, a pesquisa e a troca de experiências em todos os conteúdos do currículo escolar e, para além dele, um amplo centro cultural composto por três segmentos interligados: o Centro de Memória da Educação, espaço de guarda e preservação do acervo sobre a memória escolar de Minas Gerais e lócus privilegiado para estudos e pesquisas no campo da história da educação; o Laboratório de Currículos, que oferecia cursos de atualização em todas as áreas do conhecimento, e a Biblioteca do Professor, uma coleção em torno de 50 mil títulos, uma das de maior potencial no Brasil, referência nos temas educacionais e detentora de umas das coleções raras do Centro Regional de Pesquisas Educacionais (CRPE), do Instituto Nacional de Estudos e Pesquisas Educacionais (Inep), do antigo Instituto de Recursos Humanos João Pinheiro, que funcionou no campus do bairro Gameleira, em Belo Horizonte. 
Figura 1 - Sala de aula inspirada no ensino tradicional, no prédio da Praça da Liberdade, em 1998

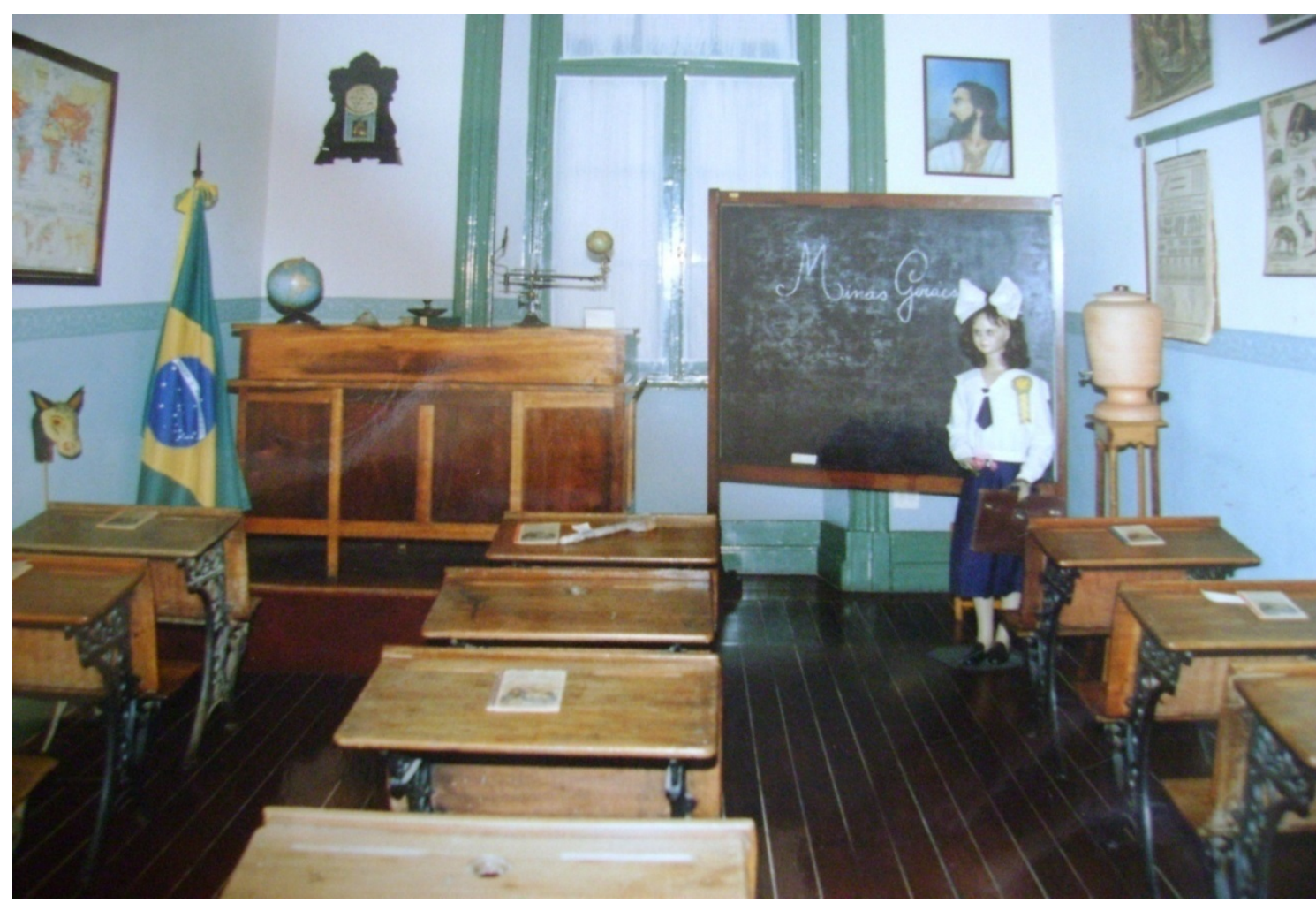

Fonte: Centro de Memória da Educação, hoje Museu da Escola “Professora Ana Maria Casasanta Peixoto”.

Na entrevista, gravada no programa de história oral do museu em abril de 2002, Ana Maria fala de como poderia parecer estranho o desenvolvimento de um trabalho dessa natureza numa secretaria de educação, gestora das políticas públicas do setor no estado, preocupada com a normatização do ensino e com um enorme contingente de professores e funcionários públicos. Disse: “[...] pode parecer curioso o desenvolvimento de um projeto sobre o passado num lugar que deve ter os olhos voltados para o futuro", ressaltando que, embora a Secretaria de Educação não tivesse tradição nessa área, havia assumido o compromisso com a recuperação e a preservação da história da educação mineira: “Este é hoje o diferencial que torna a Secretaria de Minas pioneira no campo do resgate da memória da educação no Brasil”, afirmou. A professora discorreu sobre o significativo investimento financeiro feito na operacionalização das ideias que gestaram o centro, especialmente as que criaram as condições de identificação, recolha, tratamento 
do acervo e montagem da primeira exposição que inaugurou o Centro de Memória da Educação, hoje o museu que leva seu nome, numa justa homenagem.

\section{Diretrizes do trabalho no projeto original do museu da escola}

[...] se a educação tem na cultura sua matériaprima, esta, por sua vez, depende da educação para se perpetuar e renovar. Nesse sentido, preservar a memória da escola é também preservar a nossa cultura ${ }^{6}$.

O objetivo central do projeto que orientou o trabalho nos três segmentos do Centro de Referência do Professor constituiu um grande desafio: promover a formação continuada do professor da rede pública, alcançando os aspectos políticos e pedagógicos, culturais e tecnológicos, em busca de sua autonomia profissional. Este desafio implicava realizar um trabalho de amplo espectro que favorecesse resgatar sua identidade, fortalecer sua noção de cidadania, ancorar sua busca de saber quem sou... de onde vim... pra onde vou. Tais indagações, próprias de uma profissão pontuada por crises de identidade e pela perda das referências, se agravavam num mundo cada vez mais globalizado. Por isso, também implicava a tarefa de possibilitar ao professor o conhecimento da história da profissão docente e, principalmente, levá-lo a refletir sobre o significado de seu papel na sociedade, ao longo da história.

O museu teve função preponderante no alcance desse objetivo, definindo como proposta geradora de seu trabalho, a partir da República, a valorização da escola e dos professores, suas práticas pedagógicas, os materiais didáticos utilizados e métodos e técnicas de ensino. A ênfase de suas coleções está centrada em objetos referentes à cultura material escolar ${ }^{7}$, o que nos permite conhecer aspectos da história que se passou nas escolas mineiras. O museu constitui um espaço privilegiado para estudo, pesquisa e reflexão sobre a educação escolar e a profissão docente. Testemunha expressiva do

\footnotetext{
${ }^{6}$ Do artigo "A memória da escola”, já referido.

${ }^{7}$ Embora existam nas coleções do museu, não se priorizou a guarda documental de leis, decretos e portarias que regulamentaram a educação em Minas Gerais ao longo do tempo, uma vez que esses documentos já tinham seu próprio espaço de salvaguarda, como o Arquivo Público Mineiro.
} 
passado, registro de costumes, comportamentos, ideologias e práticas de ensino, o museu seduz e emociona. Sua meta principal foi, desde sempre, realizar um trabalho sistemático de identificação e preservação dos bens materiais e imateriais relativos à história da educação em Minas, num grande esforço para evitar a dispersão e o descarte, ainda comuns em nossa cultura. A forma de comunicar ao público o significado de suas coleções foi sempre cuidadosamente definida na museografia adotada, utilizando um discurso argumentativo e teatralizado e, por isso mesmo, "com recursos de sedução maiores, uma vez que à mudez dos objetos se acrescenta a eloquência própria de sua presença", ressaltou a professora Ana Maria em seu depoimento. Com os recursos museológicos usados, puderam-se reconstituir os ambientes escolares e, favorecer ao público aproximar-se "do que pode ter sido" uma sala de aula em tempos passados, o que também se observa nas fotografias do banco de imagens. $O$ material exposto impressiona o visitante, tomado por sentimentos vários durante o percurso naquele ambiente, revelando a emoção de voltar à escola daquele tempo, seja o seu próprio, dos pais, ou avós, reconhecido em fotos, objetos e documentos guardados por familiares. Assim ocorreu com o jornalista e escritor Affonso Romano de Santana que, após uma visita, escreveu uma crônica, da qual destacamos:

[...] a antiga Secretaria de Educação hoje convertida em Centro de Referência do Professor, onde há o mais comovente museu sobre a escola pública do princípio do século. Aquelas carteiras de madeira, os tinteiros, os cadernos Avante e Companheiro, as gravuras de alfabetização com a menina Lili, a propaganda educacional do Estado Novo... ${ }^{8}$

\section{Organização do acervo e das coleções do museu da escola}

O acervo inicial, vindo da exposição "Era uma vez uma escola”, foi sendo ampliado, tendo como foco a história do ensino em todos os seus aspectos - o das instituições, o dos atores, o dos conteúdos. A entrevista com Ana Maria foi bastante esclarecedora sobre como se deu a captação do material à medida que ia sendo conseguido, quase sempre por meio de doações ou empréstimo. Ela narrou como parava

\footnotetext{
${ }^{8}$ Publicado no Jornal O Globo, $2^{\circ}$ Caderno, 21 de maio de 1996.
} 
o carro na porta das escolas nas quais acreditava poder encontrar material escolar passível de doação e exposição, identificava-se junto ao diretor, que a encaminhava, geralmente, ao porão da escola, deixando-a auxiliada pelos funcionários que cuidavam da limpeza. Foi assim, movida por seu faro investigativo, auxiliada por colegas e, mais tarde, por estagiários e funcionários da Secretaria que vieram a compor sua equipe de trabalho, que o acervo foi sendo, lentamente, ampliado. Outra questão apontada na constituição do Museu da Escola foi ter sido resultado de "um longo processo de trabalho que se deu da prática para a teoria", como a professora sempre deixou claro.

Figura 2 - Tinteiro, caneta de pena e tinta

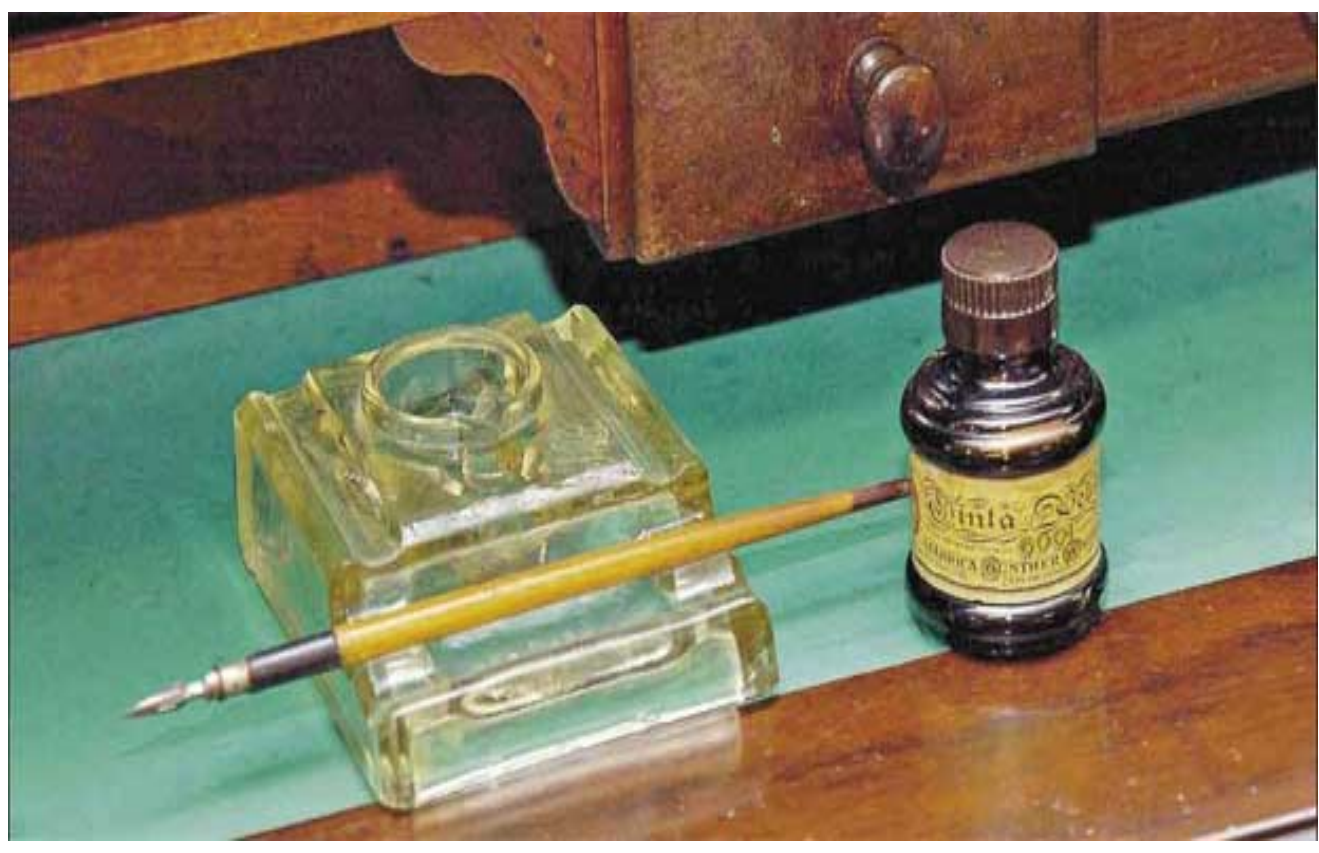

Fonte: Coleção do Museu da Escola.

Após a inauguração do centro, um novo plano de trabalho teve início, uma vez que a constituição do acervo não poderia se esgotar na obtenção dos documentos e objetos. Era preciso levar em conta que o trabalho numa instituição museológica tem por base três dimensões: preservação, pesquisa e comunicação. Portanto, era necessário buscar apoio de profissionais especializados nesse campo para atualizar os procedimentos referentes à organização, à catalogação e ao armazenamento do acervo, de acordo com os padrões museológicos. Necessário também levar em conta a especificidade da 
entidade mantenedora, a Secretaria de Educação, que não tinha em seus quadros de funcionários profissionais qualificados para o trabalho que o museu exigia. Ao lado disso, a preocupação em evitar que o acervo ficasse simplesmente 'guardado', nada contribuindo para a compreensão do processo histórico de evolução do ensino, o que levou à realização de pesquisas, visando a contextualizar cada peça na trama histórica, em suas múltiplas versões. Tais objetos constituem signos tangíveis das maneiras de fazer e pensar a educação escolar ao longo da história da educação mineira. Para levar a termo uma das mais importantes funções de um museu, a comunicação, era preciso organizar exposições de longa duração e temáticas que favorecessem a fruição do conhecimento sobre a memória da educação no estado, bem como desenvolver sua ação educativa. Para tanto, e para atrair um público maior, fazia-se necessário divulgar nas escolas, entre professores e alunos de todos os níveis e modalidades de ensino e entre os pesquisadores do campo, a abertura da nova instituição.

A partir dessas etapas, foi-se delineando um trabalho mais sistematizado. A primeira delas, a organização das coleções que compõem seu acervo: mobiliário, livros e manuais escolares, cartilhas de alfabetização, objetos do saber, registros da vida escolar, banco de imagens e, a partir de 1996, o banco de depoimentos orais. Como museu de tipologia histórica, sua missão precípua foi coletar, tratar, preservar, estudar, expor e divulgar objetos e documentos relacionados à educação escolar de Minas Gerais, a partir do período republicano. O acervo é composto por peças de mobiliário, quadros-negros, livros, cartilhas, cadernos, lousas, palmatórias, tímpanos, sinos, cartazes, mapas, globos, fantoches, histórias-mudas, tabuadas, estojos, canetas de pena, tinteiros, lápis e réguas; produções de professores, como planos de aula, documentos textuais, cartazes; produções de alunos, como jornais escolares, exercícios, redações e provas; registros escolares, como livros de matrícula, livros de ponto, livros de ocorrência, cadernetas de chamada e diplomas; suportes pedagógicos utilizados pelo professor, como livros, programas e manuais de ensino, revistas e jogos pedagógicos; objetos tridimensionais, como os planisférios e aqueles próprios do ensino de ciências naturais. Uma boa amostra desse acervo consta do primeiro catálogo, elaborado em 1998, momento em que o Centro de Memória da Educação foi renomeado Museu da Escola de Minas Gerais. 
As peças do acervo oferecem pistas para a compreensão das concepções educacionais, as práticas e as relações que se estabeleceram entre os sujeitos da educação nas escolas do passado. Estes artefatos são portadores de valores atribuídos por um longo processo social, histórico e de construção da memória e traduzem a dimensão material do processo de produção e reprodução social nas escolas mineiras ao longo do tempo. Assim, eles não valem por sua singularidade, mas pela capacidade de proporcionar o conhecimento de uma manifestação social, expressiva de uma das mais importantes formas de inserção do indivíduo na sociedade - a escola. Neste sentido, a palmatória é exemplar, uma vez que, mais que um instrumento de castigo relacionado às primeiras décadas do século $\mathrm{XX}$, é um objeto que suscita questionamentos sobre os processos e mecanismos de disciplina presentes na escola em um período mais alargado.

Figura 3 - Palmatória

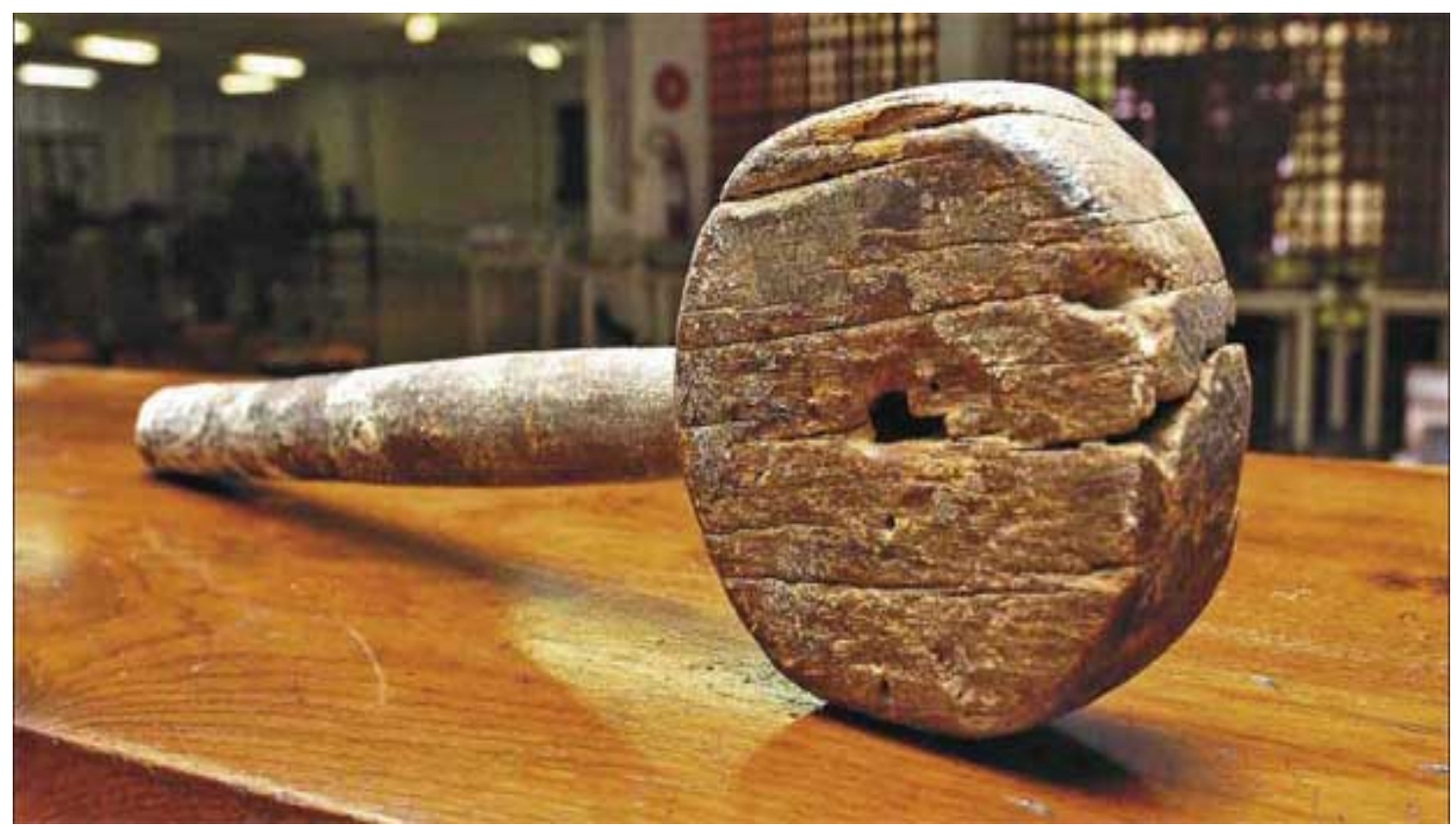

Fonte: Coleção Museu da Escola. 
Os depoimentos [orais] possibilitaram a utilização da memória como fator dinâmico de interação entre o passado e o presente, permitindo clarear aspectos importantes da educação, especialmente os relacionados à ideologia, às mentalidades e ao cotidiano escolar. ${ }^{9}$

Segundo Thompson (1992), "a história oral é tão antiga quanto a própria história” e, portanto, legítima como fonte, uma vez que a história escrita foi história oral em sua origem - essa última foi a primeira espécie de história existente, quando a tradição oral era a única via de transmissão do saber e da cultura nas sociedades pré-letradas.

Neste sentido, com a criação do museu houve expectativa com o desenvolvimento de um projeto específico para a recuperação da memória do ensino mineiro por meio das fontes orais. Era como dar vida e movimento ao acervo, buscar compreendê-lo à luz dos atores que se utilizaram daqueles bens históricos, na qualidade de aluno ou professor. Além de alargar as fontes disponíveis para a pesquisa histórica, seria também uma forma de possibilitar às atuais e futuras gerações o acesso a versões mais amplas e plurais da história da educação em Minas Gerais. Este foi o compromisso que assumimos, a partir de 1996, no Museu da Escola. Tivemos um período de estudos e pesquisas sobre os usos da história oral na educação e participamos de congressos relativos à oralidade como método de trabalho na recuperação da história. Fizemos um movimento de aproximação com grupos que desenvolviam projetos de história oral, como a Faculdade de Filosofia, Ciências e História (Fafich/UFMG), a Faculdade de Educação (FaE) da UFMG, o mestrado em Educação da PUC/MG, o grupo de Projetos Institucionais da Assembleia Legislativa de Minas Gerais e pesquisadores de outros estados brasileiros.

O trabalho teve início a partir de um mapeamento de instituições, reformas de ensino, movimentos e tendências de relevância na educação e de um levantamento de nomes de pessoas ligadas à educação e à cultura em Minas Gerais. Professores de várias

\footnotetext{
${ }^{9}$ Extraído da palestra da professora Ana Maria Casasanta, na Semana de Museus, mai. 2005.
} 
áreas do conhecimento, autoridades, como ex-secretários de educação, governadores, ministros e personalidades - como escritores e artistas plásticos - gravaram seus depoimentos. As professoras contribuíram sobremaneira com suas memórias para ampliar o quadro de referências sobre a história da educação escolar no estado. A meta principal, constituir um banco de depoimentos orais como fonte para a pesquisa historiográfica foi se ampliando, uma vez que os entrevistados se mostraram doadores em potencial, guardavam documentos e objetos referentes à sua própria história de vida estudantil ou no magistério. Ao convidá-los para gravar o depoimento, nós os sensibilizávamos para reverem seus guardados. Muitos traziam doações já no momento da entrevista; outros levavam mais tempo até perceber que, no museu, o que guardavam teria um papel importante e a visibilidade que em suas casas não poderiam ter. Entre tantas, o acervo de uma das professoras do Programa Brasileiro-Americano de Assistência ao Ensino Elementar (Pabaae), do convênio MEC-Usaid ${ }^{10}$, que vigorou entre 1957 e 1964, sendo Minas Gerais o polo irradiador daquela política para todo o Brasil. Outro acervo importante foi o que deu origem ao Arquivo Alda Lodi ${ }^{11}$, hoje a maior coleção do museu, constituída por uma biblioteca de grande porte e mais de mil documentos referentes à trajetória desta professora, figura de destaque na história da educação mineira.

\footnotetext{
${ }^{10}$ United StatesAgency for InternationalDevelopment, organismo americano que estabeleceu convênios de assistência técnica e cooperação financeira à educação brasileira, em períodos diversos.

11 A organização deste acervo constituiu parte das atividades que realizamos no mestrado no PPGE/FaE/UFMG, entre 2008 e 2010, que deu origem à dissertação "Alda Lodi, entre Belo Horizonte e Nova Iorque: um estudo sobre formação e atuação docentes - 1912/1932", sob a orientação do profo dr. Luciano

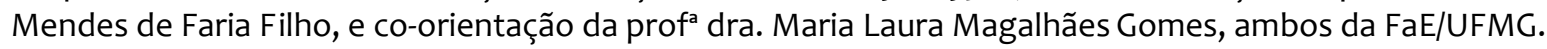


Figura 4 - Depoimento da profa Alda Lodi - maio 2000

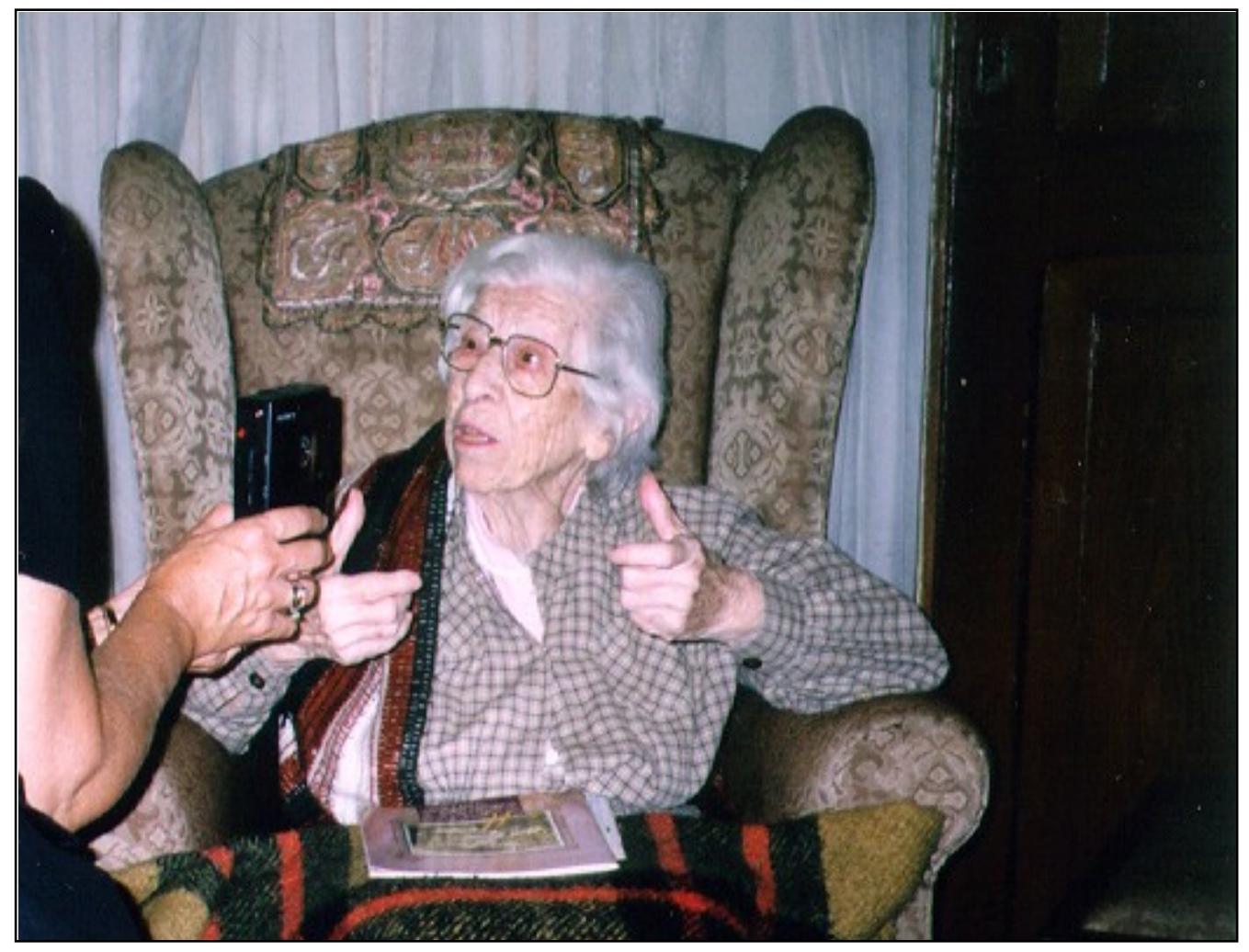

Fonte: Banco de Depoimentos Orais do Museu.

O suporte usado foi o vídeo, naquele momento, a tecnologia disponível no museu. Eventualmente, e de acordo com as condições dos entrevistados, a fita cassete também foi utilizada, sendo posteriormente transcrita. O acervo, em torno de 300 fitas de vídeo e 600 horas de gravação, oferece hoje uma diversidade de temas para a pesquisa: histórias de vida de professores e depoimentos temáticos; o movimento pela Escola Nova; o movimento grevista no estado; a história institucional da Secretaria de Educação, a partir de 1962, na fala dos antigos secretários; instituições escolares importantes como a Escola Normal Modelo e a Escola de Aperfeiçoamento; o trabalho de educadoras como Helena Antipoff; temas como canto orfeônico nas escolas, arte, educação e cultura, alfabetização, entre outros.

A coordenação do programa de história oral assumiu outros trabalhos que vieram a se constituir em vertentes importantes e iniciativas bem-sucedidas. Dentre tais iniciativas, destacamos a campanha de educação patrimonial intitulada "Em Minas, memória é coisa de futuro", comemorativa dos 10 anos do museu, lançada no estado em 
2004, com apoio do Instituto Estadual para o Patrimônio Histórico e Artístico de Minas Gerais (lepha). Esta campanha teve por objetivo identificar bens patrimoniais referentes à história da educação nas escolas mineiras, não mais para trazê-los ao Museu da Escola, mas para dar início a uma política de preservação da cultura escolar e incentivar a criação de espaços de memória no estado. A partir desta campanha, o museu teve oportunidade de realizar uma atividade de extensão, apoiando e orientando a criação do primeiro museu da escola do interior de Minas, na cidade de Oliveira, um interessante trabalho levado a efeito por uma equipe constituída na prefeitura daquele município. Outro produto desta campanha foi a criação do Museu Virtual da Memória da Educação Mineira, que reuniu 505 peças do acervo histórico, artístico e bibliográfico encontrado durante a campanha, em 21 escolas de 14 municípios mineiros, disponível no sítio eletrônico da Secretaria de Educação.

\section{Preservação da memória da educação em Minas Gerais: uma história sendo escrita}

A trajetória do Museu da Escola, em seus quase vinte anos de existência, é marcada por três períodos tão distintos quanto significativos. O primeiro, entre 1994 e 2005, período de apoio institucional irrestrito das administrações que passaram pela Secretaria da Educação. Nesse tempo, o museu ocupou o prédio histórico da Praça da Liberdade, fase de constituição e expansão, pleno funcionamento e cumprimento de sua função social, firmando-se como experiência modelar no Brasil.

A partir de 2005, instalou-se uma fase caótica, marcada por uma série de acontecimentos que anunciavam a extinção do Centro de Referência do Professor. Não havia diálogo de parte do governo, nem mesmo da administração central da secretaria para com os profissionais que coordenavam os serviços de seus três segmentos. As informações vinham pela imprensa, anunciando que alguns dos prédios históricos da Praça da Liberdade seriam repassados à iniciativa privada. Estava em curso o projeto Circuito Cultural Praça da Liberdade, que ali deveria instalar novos museus, cinemas, teatros, centros culturais, como o do Banco do Brasil, da TIM Telefonia, da empresa Valle 
do Rio Doce, o da Orquestra Sinfônica de Minas Gerais e da OGX, o Museu das Minas e do Metal. Entendemos a importância dessa iniciativa, mas não o fato de que a educação não tivesse sido incluída num projeto como esse, dada a indissociabilidade, universalmente compreendida, entre educação e cultura.

Este período de profundas transformações no trabalho que se desenvolvia no museu, a perda de investimentos financeiros, o desinteresse das autoridades ${ }^{12}$ que deveriam zelar pela preservação do patrimônio educativo-cultural, já recuperado e organizado, levaram-nos a uma grande preocupação quanto ao destino que poderia ser dado a ele. Em razão da responsabilidade com sua preservação, procuramos apoio dos profissionais do Instituto do Patrimônio Histórico e Artístico de Minas Gerais (lepha) para que se providenciasse o tombamento ${ }^{13}$ do acervo do museu, o que foi feito por seu conjunto e não por meio de um inventário, como seria ideal. Isso foi feito em tempo recorde, de modo a resguardar suas coleções e evitar maiores perdas do que já estavam ocorrendo. Em consequência de tais decisões, o museu perdeu seu espaço privilegiado ${ }^{14}$ na Praça da Liberdade, sendo transferido para o Instituto de Educação de Minas Gerais (IEMG), onde funcionou precariamente por cinco anos, entre abril de 2007 e junho de 2011. Instalar o museu no IEMG foi uma decisão arbitrária, tomada apressadamente em gabinetes, desrespeitando os órgãos competentes ligados à preservação da memória da cidade e do espaço público edificado em Belo Horizonte. Tais órgãos não concordavam com a retirada do Museu da Escola da Praça de Liberdade; argumentavam que o IEMG era um espaço legítimo, mas inadequado para instalar o museu, visto ser uma instituição escolar de grande porte, que enfrentava enormes dificuldades próprias de seu universo de 6 mil alunos, da educação infantil ao ensino médio.

\footnotetext{
${ }^{12}$ Na própria Secretaria, com o passar do tempo e das sucessivas administrações, podia-se observar uma visão romântica em relação ao Museu da Escola, um espaço interessante para se levar visitantes ilustres, o que era completamente alheio aos seus objetivos, à sua origem e à sua função social.

${ }^{13}$ O prédio histórico onde funcionava o museu era tombado pelo Instituto do Patrimônio Histórico e Artístico de Minas Gerais (lepha), mas não o acervo ali abrigado.

${ }^{14}$ Havia, entre nós, equipe de trabalho, o comentário de que o Museu da Escola, situado no prédio histórico da Educação era como "santo no oratório", devido à pertinência de um ao outro.
} 
Para evitar esse desfecho, aconteceram inúmeros debates em reuniões de instituições diversas que tentavam demover o governo de levar a termo tal decisão. Houve intensa movimentação dos professores e historiadores da educação da FaE/UFMG em favor da permanência do museu em seu lugar de origem. Apesar de todos os protestos registrados pela mídia impressa e televisiva, envolvendo autoridades, políticos, antigos professores, personalidades locais e pesquisadores do Brasil e do exterior, a mudança ocorreu para o grande salão do IEMG. Este espaço não permitia organizar exposições da forma ideal, o que transformou o museu num gabinete de curiosidades, comprometendo as visitas guiadas, como também a organização e armazenamento de suas coleções, do que resultou o caos no museu que, por mais de uma década, havia encantado o público visitante com suas exposições de longa duração, suas temáticas e a realização de eventos e ciclos de estudos. Esse estado de coisas trouxe enorme prejuízo ao trabalho cotidiano da instituição, principalmente no que se refere à ação educativa e ao atendimento aos pesquisadores. Nesse período, fizemos um grande esforço pela salvaguarda de seu acervo, atuando literalmente como 'guarda e vigia', redobrando sobre ele nossa atenção, buscando apoio que, particularmente, sempre encontramos entre os professores da FaE/UFMG. Mas, lamentavelmente, perdemos algumas peças, tanto entre as que estavam em exposição, quanto entre as que estavam na reserva técnica, devido às condições adversas dos cômodos em que haviam sido colocadas (nos porões do IEMG) e até mesmo por roubo, uma vez que as instalações não ofereciam nenhuma segurança. Portanto, foi desastroso o saldo desse período de cinco anos de abandono institucional, sem nenhum investimento, além de expor o acervo a risco.

O terceiro período deu-se a partir de fevereiro de 2012, quando o museu foi novamente transferido de local, desta vez para o campus da Secretaria da Educação, no bairro Gameleira, muito distante de seus dois endereços anteriores, local de difícil acesso para professores e alunos que formam seu público mais assíduo.

Definitivamente afastado da área mais central da cidade e do chamado circuito ou corredor cultural, também foi perdendo sua função social mais ampla, por estar distante do olhar curioso dos que passavam à sua frente, dos caminhantes da Praça de Liberdade, do visitante eventual, surpreendendo, aos que haviam frequentado a escola pública em 
tempos pretéritos, por representar um lugar de memória tão familiar. Outra perda importante na visitação cotidiana foi a dos guias, assíduos com seus grupos de turistas, que não mais conseguiram levar o grande público que sempre levavam, uma vez que a distância e as dificuldades típicas do trânsito nas grandes cidades inviabilizam o trajeto.

\section{Considerações sobre o futuro do museu da escola}

As questões relativas à preservação da memória no Brasil são por demais conhecidas e veiculadas pelas diversas mídias que se interessam pelo tema. Mais especificamente, nos eventos do campo da história da educação, historiadores e pesquisadores de áreas afins denunciam. Por outro lado, envidam esforços para que o poder público e os órgãos competentes ligados ao patrimônio elaborem políticas que efetivamente contribuam para a recuperação e preservação dos bens históricos referentes à herança educativa e cultural de municípios, regiões e estados brasileiros. Procuramos acompanhar o que vem ocorrendo em outros estados no tocante à preservação da memória escolar e neles encontramos um quadro semelhante ao de Minas Gerais. Da mesma forma, procuramos observar esse movimento no Brasil, por meio de publicações de colegas pesquisadores e de discussões levadas aos diversos congressos e eventos dos quais participamos. O IX Congresso Luso Brasileiro de História da Educação, sobre a temática “Rituais, Espaços e Patrimônios Escolares”, edição 2012, realizado em Lisboa, foi um momento singular para tal observação. Entre tantos trabalhos, a pesquisadora Rosa Fátima de Souza, numa mesa-redonda, trouxe à necessária discussão o título "Preservação do patrimônio escolar no Brasil: notas para um debate"15. A partir do emblemático tombamento de um conjunto de 126 escolas, feito pelo governo de São Paulo em 2010, a pesquisadora reforçava a necessidade da ação do poder público no campo da preservação do patrimônio edificado, ao mesmo tempo em que questionava a forma como isso acontecia, apontando para a amplitude dos domínios do patrimônio escolar, que vai muito além dos prédios e das particularidades de sua arquitetura. Disse então a pesquisadora:

\footnotetext{
${ }^{15}$ Cf. Revista Linhas, Florianópolis, v. 14, n. 26, jan./jun. 2013. p. 199-221.
} 


\begin{abstract}
Esta memória, instituída e projetada na arquitetura das primeiras escolas normais e grupos escolares do estado de São Paulo, impõe-se no presente como um alerta e um brado de denúncia. Ela faz relembrar dados e episódios menos glamorosos da escola republicana no País, como a insistente relação entre escola e desigualdades sociais, exclusão das crianças das camadas populares, alta seletividade do ensino e diferenciação entre tipos de escolas e grupos sociais atendidos. Não resta dúvida sobre a disputa pela memória posta em questão. Neste caso, a religação com o passado aviva o sintoma agudo e permanente de crise, de esgarçamento e de esvanecimento do valor social e cultural da escola na sociedade contemporânea.
\end{abstract}

Esta afirmação, tão eloquente quanto a da professora Ana Maria, em destaque no início deste artigo, diz muito em relação à decisão do governo mineiro de retirar o Museu da Escola do prédio histórico da Praça da Liberdade, num momento em que se erguia ali um espaço para sediar a cultura mineira. As autoridades que assim decidiram não levaram em conta a associação de tal fato à histórica desvalorização da educação por sucessivos governos ao longo do tempo. Foi um posicionamento arrogante e autoritário que não ouviu os apelos dos que tentaram evitar aquele grande equívoco.

Em que pese essa trajetória, o Museu da Escola, por suas origens, por força de seu potencial, pelo reconhecimento de sua importância nos meios acadêmicos em Minas Gerais e no Brasil, mantém vivas as possibilidades de revitalização e retomada de sua missão original - a valorização da escola e da profissão docente, a preservação da memória do ensino de Minas Gerais, um patrimônio público, que não pode ser sonegado aos olhos e à fruição de todo visitante, indistintamente. Embora distante do circuito dos museus em Belo Horizonte, é necessário que se mantenha a expectativa de que, num futuro próximo, seja possível reverter esse estado de coisas, devolvendo o Museu da Escola a quem se destina - a toda a sociedade.

Sua trajetória acidentada impediu que muitos projetos fundamentais fossem realizados; entre eles, a implantação do Plano Museológico, a informatização e a disponibilização via rede mundial de computadores, condições para que o Museu da Escola, e seus serviços, trabalhem dentro dos padrões modernos da museologia e dos amplos recursos tecnológicos disponíveis. Outra questão de suma importância é criar a Associação dos Amigos do Museu da Escola, impedida em diversas ocasiões por 
dirigentes da Secretaria de Educação. Esta figura jurídica é o elemento de ligação entre o museu, sua entidade mantenedora e a sociedade. Sua função principal é contribuir para boas iniciativas que protejam a instituição museológica de decisões arbitrárias, que venham a lhe causar prejuízos de qualquer natureza. Entendemos que, se o museu tivesse sua associação criada e atuante, provavelmente se teriam evitado os percalços ocorridos.

Nessa terceira fase de mudança de local, tivemos a colaboração do escritor e poeta mineiro Bartolomeu Campos Queirós, contrário à retirada do museu do circuito dos museus na cidade, inconformado com a improvisação imposta à instituição que, segundo ele, 'mudava para continuar na mesma situação precária', sem definição sobre seus destinos futuros. Nosso querido escritor, um antigo 'amigo do museu', já adoentado, veio a falecer em meio a esse processo, mas deixou entre nós uma inquietação ainda mais profunda sobre o fato de o museu ficar ao sabor de políticas momentâneas e de pessoas alheias à sua história, que não têm paixão pela causa e não levam em conta suas necessidades. A indignação de Bartolomeu nos fez rememorar o filósofo Walter Benjamim: “O passado comportava outros futuros além deste que realmente ocorreu ${ }^{16 ”,}$ tendo em vista o lugar privilegiado que o museu ocupou, no contexto da cidade, por mais de uma década. Entre tantas expectativas em relação a seu futuro, a principal é que o poder público do estado e os órgãos responsáveis pelos acervos históricos em Belo Horizonte, usando de suas atribuições, reconheçam sua importância histórica e lhe definam um espaço adequado e definitivo para instalá-lo, de modo a preservá-lo para as gerações futuras. Considerando as dificuldades causadas pelas mudanças de endereço e a perda de acervo, é fundamental que receba o tratamento condizente com sua importância histórica, garantindo sua integridade e o cumprimento pleno de sua função social.

Esta experiência nos fez entender que a condição fundamental para a sustentabilidade de um museu está ligada à entidade mantenedora. Esta foi uma das questões que levamos à discussão no seminário do qual participamos, em 2007, na

\footnotetext{
${ }^{16}$ A citação completa é "A principal responsabilidade do homem é revelar o esquecido, mostrar que o passado comportava outros futuros além deste que realmente ocorreu", da obra Memória e Esquecimento (parte 1) de Walter Benjamim (1892-1940), filósofo judeu alemão.
} 
Faculdade de Educação da Universidade de Brasília (UnB), evento preparatório para a criação do Museu da Educação do Distrito Federal. É fundamental, para a sobrevivência de um lugar de memória, que seja regido por entidades mais permanentes, menos afetas a decisões políticas momentâneas, o que pode colocar em risco ideias plenas de legitimidade e de grande valor social e cultural. Nos momentos críticos enfrentados pela extinção do Centro de Referência do Professor, em que a própria continuidade do Museu da Escola corria risco, hipóteses foram levantadas sobre a conveniência e a possibilidade de transferir sua guarda à Secretaria de Estado de Cultura de Minas Gerais, que gerencia vários museus em todo o estado, tendo em vista sua tradição no trato com a história e a cultura mineiras. Outra possibilidade discutida à época foi integrar o museu à UFMG, considerando o amplo debate que a Faculdade de Educação realiza no campo da história da educação no âmbito de seus grupos de pesquisa, como o Centro de Documentação, Pesquisa e Memória (CEDOC) e o Centro de Pesquisa em História da Educação (GEPHE). A UFMG conta também com a Rede de Museus, constituída pelos diversos espaços de memória de suas unidades, rede esta que vem buscando o aprimoramento na preservação dos acervos históricos da instituição, bem como a proposição de políticas públicas referentes à preservação do patrimônio acadêmico-científico. Embora o intenso debate ocorrido sobre os destinos do Museu da Escola, à época, a administração da Secretaria de Educação se eximiu de tomar uma decisão mais adequada ao seu futuro. Essa decisão poderia ter garantido a preservação da concepção original do Museu da Escola bem como das diretrizes que orientaram sua criação. 


\section{Referências}

FONSECA, Nelma Marçal Lacerda. Alda Lodi, entre Belo Horizonte e Nova lorque: um estudo sobre formação e atuação docentes 1912-1932. UFMG, Faculdade de Educação. 2010. Dissertação de Mestrado.

PEIXOTO, Ana Maria Casasanta. Banco de Depoimentos Orais, Museu da Escola "Professora Ana Maria Casasanta Peixoto". Depoimento oral de 4 horas de gravação, transcrito, abr. 2002.

PEIXOTO, Ana Maria Casasanta; PRATES, Maria Helena de Oliveira. Guia de Fontes para o Estudo do Ensino Primário e Normal em Minas Gerais. Belo Horizonte, UFMG: FAE, FAPEMIG, 1994.

THOMPSOM, PAUL. A voz do passado: história oral. Rio de Janeiro: Paz e Terra, 1992. 385p.

Recebido em: 14/02/2014 Aprovado em: 23/04/2014

Universidade do Estado de Santa Catarina - UDESC Programa de Pós-Graduação em Educação - PPGE Revista Linhas Volume 15 - Número 28 - Ano 2014 revistalinhas@gmail.com 